\title{
LIVING QUR'AN DAN HADIS DI MI NURUL UMMAH (Rutinitas, Ritual Ibadah dan Pembinaan Akhlak)
}

\author{
Muhammad Shaleh Assingkily ${ }^{1}$, Mahmud Arif ${ }^{2}$, Marhumah \\ Khamim Zarkasih Putro ${ }^{4}$ \\ Universitas Islam Negeri Sunan Kalijaga Yogyakarta \\ 12assingkily27@gmail.com, ${ }^{2 d}$ rmahmud.arif@,uin-suka.ac.id \\ 33arhumah@uin-suka.ac.id, ${ }^{4}$ 196202271992031004@uin-suka.ac.id
}

\begin{abstract}
This article examines the living Qur'an and hadith through programmatic activities in madrasah ibtidaiyah (MI). During this time, the study of living Qur'an and hadith is dominated by the area of social research, both within the scope of certain communities and the wider community. In fact, this study is important to be developed in educational institutions, as an effort to restore the "spirit" of Islamic education and to make the Al-Qur'an hadith "living text" in MI. For this reason, this study analyzes al-Qur'an hadith learning and and programmed activities at MI Nurul Ummah. The main data was obtained through interviews, observations and study of documents focused on routines, rituals, and moral guidance in MI. The focus of these activities, in terms of oral, aural, writing, and attitude aspects. Thus, fulfilling the four aspects of something is referred to as the effort to live the Qur'an and hadith.
\end{abstract}

Keywords: Living Qur'an and hadith, MI, Moral guidance, Rituals, Routines.

Abstrak: Artikel ini mengkaji living Qur'an dan hadis melalui kegiatan terprogram di madrasah ibtidaiyah (MI). Selama ini, kajian living Qur'an dan hadis didominasi oleh wilayah penelitian sosial, baik dalam lingkup komunitas tertentu maupun masyarakat luas. Padahal, kajian ini penting dikembangkan pada lembaga pendidikan, sebagai upaya mengembalikan "ruh" pendidikan Islam dan menjadikan alQur'an hadis "teks hidup" di MI. Untuk itu, penelitian ini menganalisa pembelajaran al-Qur'an hadis dan kegiatan terprogram di MI Nurul Ummah. Data utama diperoleh melalui wawancara, observasi dan studi dokumen yang terfokus pada rutinitas, ritual, dan pembinaan akhlak di MI. Fokus kegiatan tersebut, ditinjau dari aspek oral, aural, writing, dan attitude. Sehingga, terpenuhi empat aspek sesuatu disebut sebagai upaya living Qur'an dan hadis.

Kata Kunci: Living Qur'an dan hadis, MI, Pembinaan Akblak, Ritual, Rutinitas.

\section{PENDAHULUAN}

Pendidikan merupakan bagian tak terpisah dari keberlangsungan hidup manusia. Untuk itu, Islam menganjurkan

AR-RIAYAH : Jurnal Pendidikan Dasar Vol. 4, no. 1, 2020

IAIN Curup - Bengkulu l p ISSN 2580-362X; e ISSN 2580-3611 http://journal.iaincurup.ac.id/index.php/JPD 
sejak dini anak memperoleh pendidikan, khususnya pembelajaran yang bersumber dari bujjah al-Islam yaitu, al-Qur'an dan hadis. Hal ini mendasari al-Qur'an dan hadis menjadi mata pelajaran "wajib" di madrasah maupun sekolah.

Secara tekstual, pembelajaran al-Qur'an hadis diajarkan kepada anak mulai dari jenjang MI hingga perguruan tinggi. Hal ini terlihat dari pengembangan bahan ajar mata pelajaran al-Qur'an hadis yang beredar dari tahun ke tahun. Namun, peningkatan upaya tekstual tersebut, agaknya berbanding terbalik dengan tinjauan aspek kontekstual. Sebab, al-Qur'an hadis masih dipandang "kaku" tertulis di buku dan minim realisasi dalam keseharian peserta didik. Padahal, al-Qur'an dan hadis didesain sebagai "open book"1, pedoman bagi umat manusia.

Keberadaan pembelajaran al-Qur'an hadis di madrasah, belum mendapat perhatian penuh dari berbagai pihak dalam upaya kontekstualisasinya. Hal ini terlihat dari berbagai penelitian tentang kontekstualitas al-Qur'an hadis selama 7 (tujuh) tahun terakhir. Latar penelitian mengkaji seputar tradisi masyarakat desa,2

1 Mahmud Arif, “Al-Qur'an As an 'Open Book' in Educational Perspective: The Significant Meaning of Pedagogical Values and Productive Reading" Sunan Kalijaga International Journal on Islamic Educational Research, vol. 3, no. 2 (2019), $\quad$ pp. 1-16. http://ejournal.uinsuka.ac.id/tarbiyah/index.php/SKIJIER/article/view/2811.

2 Miftahus Sa'diyah, "Islam and Local Culture: Living Qur'anic Studies in the Ngeruwat Bumi Culture in Balung Village" Nuansa, vol. 15, no. 2 (2018), pp. 321-332, http://dx.doi.org/10.19105/nuansa.v15i2.2061. Lihat Annisa Fadlillah, "Pembacaan Surat Al-Insyirah dan Al-Qodr pada Tradisi Bayen: Studi Living Qur'an pada Masyarakat Wonokerto Kabupaten Semarang" Tesis (Yogyakarta: Pascasarjana UIN Sunan Kalijaga, 2018). Lihat Ade Trial Ramadiputra, "Pemaknaan Al-Qur'an dan Hadis dalam Tradisi Ritual Mandi Safar di Desa Momo Kecamatan Mamosalato Kabupaten Morowali Utara Provinsi Sulawesi Tengah Studi Living Qur'an” Tesis (Yogyakarta: Pascasarjana UIN Sunan Kalijaga, 2018). Lihat Munirah, "Memorizing the Qur'an as Banjarese Bride-Price (A Study of Living Qur'an and Hadith)" Ulumuna, vol. 21, no. 2 (2017), pp. 278-297, https://doi.org/10.20414/ujis.v21i2.319. Lihat Dona Kahfi. MA. Iballa, "Tradisi Mandi Balimau di Masyarakat Kuntu: Living Hadis Sebagai Bukti Sejarah" Jurnal Living Hadis, vol. 1, no. 2 (2016), pp. 275-293, http://ejournal.uinsuka.ac.id/ushuluddin/Living/article/view/1122/1024 Lihat Yeni Angelia dan In'amul Hasan, "Merantau dalam Menuntut Ilmu (Studi Living Hadis oleh Masyarakat Minangkabau)" Jurnal Living Hadis, vol. 2, no. 1 (2017), pp. 67-82, http://ejournal.uin-suka.ac.id/ushuluddin/Living/article/view/1316/1190. Lihat Wildan Rijal Amin, "Living Hadis dalam Fenomena Tradisi Kupatan di Desa Durenan Kecamatan Durenan Kabupaten Trenggalek" Tesis (Yogyakarta: Pascasarjana UIN Sunan Kalijaga, 2017). 
komunitas,3rutinitas santri di pondok pesantren4 dan sekolah5. Terbaru, kontekstualitas al-Qur'an secara umum dipandang tepat sebagai model pendidikan dasar Islam di madrasah.6

Berdasarkan literature review di atas, diketahui bahwa masih sedikit kajian penelitian yang membahas kontektualitas (living) Qur'an dan hadis di madrasah. Padahal, madrasah merupakan "sekolah plus" dengan tambahan materi keagamaan Islam7, termasuk mata pelajaran al-Qur'an hadis.

3 Muhammad Rafi, "Living Hadis: Studi atas Tradisi Sedekah Nasi Bungkus Hari Jumat oleh Komunitas Sijum Amuntai” Jurnal Living Hadis, vol. 4, no. 1 (2019), pp. 133-158, http://ejournal.uinsuka.ac.id/ushuluddin/Living/article/view/1647/1408.

4 Hilda Nurfuadah, Didi Junaedi, dan Umayah, “Living Qur'an: Resepsi Komunitas Muslim pada Alquran (Studi Kasus di Pondok Pesantren atTarbiyyatul Wathoniyyah Desa Mertapada Kulon, Kec. Astatana Japura, Kab. Cirebon)" Diya al-Afkar, vol. 5, no. 1 (2017), pp. 1-14, http://dx.doi.org/10.24235/sqh.v5i01.3769. Lihat Faiqatul Khosyiah, "Living Hadis dalam Kegiatan Peringatan Maulid Nabi di Pesantren Sunan Ampel Jombang" Jurnal Living Hadis, vol. 3, no. 1 (2018), pp. 23-45, http://ejournal.uinsuka.ac.id/ushuluddin/Living/article/view/1363/1316. Lihat Siti Qurrotul Aini, "Tradisi Qunut dalam Shalat Maghrib di Pondok Pesantren Wahid Hasyim Yogyakarta (Studi Living Hadis)" Jurnal Living Hadis, vol. 1, no. 2 (2016), pp. 227241, http://ejournal.uin-suka.ac.id/ushuluddin/Living/article/view/1120/1022. Lihat Moh. Muhtador, "Pemaknaan Ayat Al-Qur'an dalam Mujahadah: Studi Living Qur'an di PP Al-Munawwir Krapyak Komplek Al-Kandiyas" Jurnal Penelitian, vol. 8, no. 1 (2014), pp. 93-112, http://journal.stainkudus.ac.id/index.php/jurnalPenelitian/article/download/13 43/1187. Lihat Syahrul Rahman, "Living Qur'an: Studi Kasus Pembacaan AlMa'tsurat di Pesantren Khalid bin Walid Pasir Pengaraian Kab. Rokan Hulu” Jurnal Syabadab, vol. 4, no. 2 (2016), pp. 49-71, http://dx.doi.org/10.32495/.v4i2.119. Lihat Ahmad Atabik, "The Living Qur'an: Potret Budaya Tabfiz. Al-Qur'an di Nusantara” Jurnal Penelitian, vol. 8, no. 1 (2014), pp. 161-178, http://journal.stainkudus.ac.id/index.php/jurnalPenelitian/article/download/13 46/1190. Lihat Lukman Basri, "Pemahaman dan Pengamalan Santri Pon-Pes IMMIM Terhadap Mukhtar Al-Ahadis" Jurnal Kajian Ilmu Hadis, vol. 8, no. 2 (2017), pp. 192-222, http://journal.uinalauddin.ac.id/index.php/tahdis/article/view/7228/5933.

5 Anisa Khabibatus Sholihah, "Implementasi Living Qur'an di SMP Islam Al-Azhar 26 Yogyakarta" Tesis (Yogyakarta: Pascasarjana UIN Sunan Kalijaga, 2018).

6 Muhammad Shaleh Assingkily, "Living Qur'an as A Model of Islamic Basic Education in the Industrial Era 4.0" Al-Ibtida': Jurnal Pendidikan Guru MI, vol. 6, no. 1 (2019), pp. 19-36, http://dx.doi.org/10.24235/al.ibtida.snj.v6i1.3876.

7 Muhammad Kosim, "Madrasah di Indonesia (Pertumbuhan dan Perkembangan)" Tadris: Jurnal Pendidikan Islam, vol. 2, no. 1 (2007), pp. 41-57. 
Menganalisa urgensitas kajian ini, dibutuhkan upaya mengembalikan "ruh" pendidikan Islam di madrasah melalui pembelajaran al-Qur'an hadis pada setiap tingkat. Sehingga, nilainilai Qur'ani dalam buku teks ajar yang "ter-framing” kaku dan dan pasif dibelajarkan kepada siswa, 8 dapat menjadi "hidup" dan terpatri sebagai kepribadian siswa.

Upaya ini ditujukan agar daya eksplorasi dan perkembangan siswa optimal,9 khususnya fase perkembangan anak usia dasar jenjang MI. sebab, pendidikan nilai keagamaan (melalui al-Qur'an dan hadis) yang dibelajarkan sejak dini pada siswa, berpengaruh pada pembentukan kepribadian.

Mencermati uraian tersebut, MI Nurul Ummah Kotagede Yogyakarta sebagai lembaga pendidikan dasar Islam tergolong "baru" sejak didirikan 2015 lalu, memperlihatkan kualitas pembelajaran melalui keseimbangan kegiatan di dalam dan luar kelas. Hal ini tercermin dari pelibatan berbagai pihak meliputi pimpinan madrasah, para guru dan orangtua/wali siswa, untuk membantu perkembangan potensi diri siswa di madrasah. Tidak hanya itu, upaya ini diejawantahkan dalam 3 (tiga) bentuk kegiatan di madrasah berupa rutinitas madrasah, ritual ibadah dan pembinaan akhlak.10

http://ejournal.stainpamekasan.ac.id/tadris/article/view/209. Lihat Nanang Budianto, "Implementasi Pengembangan Madrasah dan Sekolah Islam Unggulan sebagai Upaya Peningkatan Kualitas Pendidikan Islam” FALASIFA: Jurnal Studi Keislaman, vol. 8, no. 1 (2017), pp. 109-126. http://ejournal.inaifas.ac.id/index.php/falasifa/article/view/42.

8 Muhtar S. Hidayat, "Pendekatan Kontekstual dalam Pembelajaran" Insania: Jurnal Pemikiran Alternatif Kependidikan, vol. 17, no. 2 (2012). http://ejournal.iainpurwokerto.ac.id/index.php/insania/article/view/1500. Lihat Edi Suhartono, "Perubahan Pola Pembelajaran PKn yang Tekstual ke Pola Kontekstual (CTL)" Jurnal Teori dan Praksis Pembelajaran, vol. 3, no. 1 (2018), pp. 1-12. http://journal2.um.ac.id/index.php/jtppips/article/view/3883/2162.

9 Firosalia Kristin, "Efektivitas Model Pembelajaran Kooperatif Tipe STAD Ditinjau dari Hasil Belajar IPS Siswa Kelas 4 SD" Scholaria: Jurnal Pendidikan dan Kebudayaan, vol. 6, no. 2 (2016): 74-79. https://doi.org/10.24246/i.scholaria.2016.v6.i2.p74-79. Lihat Nimatul Fauziyah, "Faktor Penyebab Kejenuhan Belajar Sejarah Kebudayaan Islam (SKI) pada Siswa Kelas XI Jurusan Keagamaan di MAN Tempel Sleman" Jurnal Pendidikan Agama Islam, vol. 14, no. 1 (2017): 99-108.

10 Wawancara dengan Pak Adip Muammar Habibi, M.Pd., Kepala Madrasah (MI) Nurul Ummah Kotagede Yogyakarta. Pada hari Selasa, 01 Oktober 2019, pukul 08.30 WIB di Ruang Kepala Madrasah (MI) Nurul Ummah. 


\section{METODE PENELITIAN}

Penelitian ini menggunakan pendekatan kualitatif dengan metode deskriptif analitis. Penelitian empirik ini menganalisa pembelajaran al-Qur'an hadis dan kegiatan terprogram di MI Nurul Ummah, baik di dalam kelas maupun di luar kelas. Adapun latar pelaksanaan pembelajaran, rutinitas madrasah, dan kegiatan terprogram madrasah menjadi perhatian utama riset. Untuk itu, pemerolehan data dilakukan dengan teknik wawancara mendalam, observasi partisipan dan studi dokumentasi. Data diperoleh melalui sumber data dan data yang terdapat di madrasah. Kemudian dianalisis untuk mengungkap kebenaran empiris secara berkesinambungan dengan teknik reduksi data, penyajian data, dan penarikan simpulan.

Selanjutnya, pengujian keabsahan data dilakukan dengan teknik triangulasi (sumber dan metode) dan ketekunan pengamatan penelitian. Berdasarkan hal itu, ditemukan upaya pendidikan nilai dalam proses pembelajaran melalui tinjauan aspek moralitas Thomas Lickona dan Ajat Sudrajat. Pada gilirannya, terpenuhi 4 (empat) aspek sesuatu dikategorikan sebagai upaya living Qur'an dan hadis, yakni oral, aural, writing dan attitude.

\section{HASIL DAN PEMBAHASAN}

\section{Living Qur'an dan Hadis Melalui Rutinitas Madrasah}

Kegiatan rutinitas madrasah di MI Nurul Ummah terbagi menjadi dua, yakni aktivitas harian (daily activities) dan aktivitas tambahan (extra activities). Berdasarkan penjelasan dari M. Rofik, aktivitas harian terdiri dari tahfiz dan tahsin al-Qur'an, Jum'at murojaah, istirahat dan kudapan I-II. Sedangkan kegiatan tambahan terdiri dari semester swim, hadroh van Beethoven, dan Yearly haflah Khotmil Qur'an.11

a. Tahsin dan Tahfiz Al-Qur'an

Tahsin dan tahfiz al-Qur'an merupakan kegiatan terjadwal dalam kurikulum MI Nurul Ummah.12 Mendukung kegiatan ini, pihak madrasah mengalokasikan waktu yang "luas"

11 Wawancara dengan M. Rofik, KTU MI Nurul Ummah Kotagede Yogyakarta. Pada hari Jumat, 27 September 2019, pukul 10.11 WIB di Ruang Admisi MI Nurul Ummah.

12 Berdasarkan keterangan dari Ustaz Yuliadi Ponda (Koordinator tahfiz dan tahsin al-Qur'an MI Nurul Ummah), pada tanggal 3 Desember 2019 di Balai Murojaah. 
untuk kegiatan pembelajaran tersebut.13 Berikut diuraikan waktu pembelajaran tahsin dan tahfiz al-Qur'an di MI Nurul Ummah.

Tabel 1 . Jadwal Pembelajaran Tahsin dan Tahfiz Al-Qur'an MI Nurul Ummah

\begin{tabular}{|c|c|c|c|c|c|}
\hline No. & Kelas & Hari & Tahfiz & Tahsin & Total JP \\
\hline \multirow{6}{*}{1.} & \multirow{6}{*}{$\begin{array}{c}\text { Kelas } \\
1 \mathrm{~A}\end{array}$} & Senin & 07.35-09.00 WIB & 13.35-15.25 WIB & 195 Menit \\
\hline & & Selasa & 07.35-08.35 WIB & 13.35-15.00 WIB & 145 Menit \\
\hline & & Rabu & 07.35-09.00 WIB & 13.50-15.25 WIB & 180 Menit \\
\hline & & Kamis & 07.35-09.00 WIB & 13.35-15.05 WIB & 170 Menit \\
\hline & & Jum'at & 07.35-09.00 WIB & 13.50-15.25 WIB & 180 Menit \\
\hline & & (Seminggu) & Total: 400 Menit & Total: 475 Menit & 875 Menit \\
\hline \multirow{6}{*}{2.} & \multirow{6}{*}{$\begin{array}{c}\text { Kelas } \\
\text { 1B }\end{array}$} & Senin & 07.35-09.00 WIB & 13.35-15.25 WIB & 195 Menit \\
\hline & & Selasa & 07.35-09.00 WIB & 13.35-15.00 WIB & 170 Menit \\
\hline & & Rabu & 07.35-08.35 WIB & 13.50-15.25 WIB & 155 Menit \\
\hline & & Kamis & 07.35-09.00 WIB & 13.35-15.05 WIB & 175 Menit \\
\hline & & Jum'at & 07.35-09.00 WIB & 13.50-15.25 WIB & 180 Menit \\
\hline & & (Seminggu) & Total: 400 Menit & Total: 475 Menit & 875 Menit \\
\hline \multirow{6}{*}{3.} & \multirow{6}{*}{$\begin{array}{c}\text { Kelas } \\
2\end{array}$} & Senin & 13.35-15.25 WIB & 07.35-09.00 WIB & 195 Menit \\
\hline & & Selasa & 13.35-15.00 WIB & 07.35-09.00 WIB & 170 Menit \\
\hline & & Rabu & 13.50-15.25 WIB & 07.35-09.00 WIB & 180 Menit \\
\hline & & Kamis & 13.35-15.05 WIB & 07.35-08.35 WIB & 150 Menit \\
\hline & & Jum'at & 13.50-15.25 WIB & 07.35-09.00 WIB & 180 Menit \\
\hline & & (Seminggu) & Total: 475 Menit & Total: 400 Menit & 875 Menit \\
\hline \multirow{6}{*}{4.} & \multirow{6}{*}{$\begin{array}{c}\text { Kelas } \\
3\end{array}$} & Senin & 07.35-09.00 WIB & 13.35-15.00 WIB & 170 Menit \\
\hline & & Selasa & 07.35-08.35 WIB & 13.35-15.00 WIB & 145 Menit \\
\hline & & Rabu & 07.35-09.00 WIB & 13.50-15.05 WIB & 160 Menit \\
\hline & & Kamis & 07.35-09.00 WIB & 13.35-15.05 WIB & 175 Menit \\
\hline & & Jum'at & - & 13.50-15.15 WIB & 85 Menit \\
\hline & & (Seminggu) & Total: 315 Menit & Total: 420 Menit & 735 Menit \\
\hline \multirow{6}{*}{5.} & \multirow{6}{*}{ Kelas 4} & Senin & - & 13.35-15.15 WIB & 100 Menit \\
\hline & & Selasa & 07.35-09.00 WIB & 13.35-15.00 WIB & 170 Menit \\
\hline & & Rabu & 07.35-08.35 WIB & 13.50-15.10 WIB & 140 Menit \\
\hline & & Kamis & 07.35-09.00 WIB & 13.35-15.00 WIB & 170 Menit \\
\hline & & Jum'at & 07.35-09.00 WIB & - & 85 Menit \\
\hline & & (Seminggu) & Total: 315 Menit & Total: 350 Menit & 665 Menit \\
\hline \multirow{2}{*}{6.} & \multirow{2}{*}{$\begin{array}{c}\text { Kelas } \\
5\end{array}$} & Senin & - & 13.35-15.15 WIB & 100 Menit \\
\hline & & Selasa & 07.35-09.00 WIB & 13.35-15.00 WIB & 170 Menit \\
\hline
\end{tabular}

13 Berdasarkan keterangan dari Ustaz Yuliadi Ponda (Koordinator Tahfiz dan Tahsin MI Nurul Ummah Kotagede Yogyakarta). Pada hari Jumat, 22 November 2019, pukul 07.44 WIB di Balai Murojaah MI Nurul Ummah. 


\begin{tabular}{llcl} 
Rabu & $07.35-08.35 \mathrm{WIB}$ & $13.50-15.10 \mathrm{WIB}$ & $140 \mathrm{Menit}$ \\
\hline Kamis & $07.35-09.00 \mathrm{WIB}$ & $13.35-15.00 \mathrm{WIB}$ & $170 \mathrm{Menit}$ \\
\hline Jum'at & $07.35-09.00 \mathrm{WIB}$ & - & $85 \mathrm{Menit}$ \\
\hline (Seminggu) & Total: 315 Menit & Total: 350 Menit & $\mathbf{6 6 5}$ Menit
\end{tabular}

Sumber: Jadwal Tabfiz-Tabsin Al-Qur'an MI Nurul Ummah Tabun 2019-2020

Berdasarkan tabel di atas, terlihat bahwa jadwal pembelajaran tahfiz-tahsin di MI Nurul Ummah sangat efisien disediakan bagi siswa. Adapun perbedaan jadwal tersebut, disebabkan penekanan fokus kegiatan. Di mana tahsin difokuskan bagi siswa kelas 1-2, agar bacaan bagus dan sesuai kaidah tajwid. Sedangkan untuk kelas 3-5 lebih diluangkan waktu tahfiz, agar siswa mencapai target hafal, serta ditambah jadwal ekstrakurikuler madrasah bagi mereka.

b. Jumat Murojaah

Jumat Murojaah merupakan rutinitas madrasah yang dilaksanakan setiap hari Jumat minggu pertama di balai murojaah MI Nurul Ummah. kegiatan ini dilaksanakan dengan desain konsep formal meliputi; pembukaan oleh MC,14 pembacaan ayat suci al-Qur'an,15 siswa membaca surah al-Fatihah bersama dipimpin siswa yang akan murojaah, membaca doa untuk kedua orangtua, siswa yang bertugas murojaah membacakan 1 juz alQur'an16 untuk disimak secara seksama, kemudian siswa bermain hadrob dan salawatan, makan kudapan dari orangtua/wali siswa, 17 beruluk salam usai kegiatan murojaah, dan membersihkan balai murojaah.

Kegiatan ini diinisiasi dengan tujuan melatih keberanian siswa. Hal ini ditandai dengan praktik bacaan dan hafalan siswa di depan teman sebaya serta guru tahsin-tahfiz al-Qur'an, serta

14 MC atau pembawa acaranya adalah seorang siswa yang ditunjuk oleh Guru Tahsin/Tahfiz pada Jumat sebelumnya, diberi teks dan diminta bersiap untuk memandu acara murojaah.

15 Qori' atau Qori'ah (Pembaca ayat suci al-Qur'an) juga merupakan salah seorang siswa yang dipilih secara acak oleh guru ketika kegiatan berlangsung setiap Jumat-nya.

16 Dua orang siswa dipilih membacakan hafalannya dengan menggunakan mikrofon agar disimak bersama oleh guru dan siswa, keduanya berbagi bacaan hingga khatam 1 juz.

17 Adapun makanan ringan (kudapan/snack) yang dimakan bersama oleh siswa dan guru adalah pemberian dari orangtua siswa (wali siswa) karena senang atas terselenggaranya kegiatan seperti ini pada anak-anak mereka. 
diisi dengan upaya mengoreksi kekeliruan bacaan sebagai bentuk menjalin silaturahmi antarsiswa.18

Senada dengan upaya tersebut, Mukholisoh et.al berpendapat bahwa murojaah penting dilakukan sebagai upaya meminimalisir hambatan dalam pembelajaran tahsin-tahfiz seperti jenuh, bosan, dan malas bilamana target hafalan belum tercapai.19

Program ini sejatinya "baru" dilaksanakan sejak 2019 di MI Nurul Ummah, begitupun sambutan positif dari para wali siswa dipandang menjadi dampak nyata yang dirasakan kebermanfaatannya bagi sivitas MI Nurul Ummah. Bahkan, siswa juga merasa "tertantang" untuk mampu mencintai alQur'an sejak dini melalui bacaan dan hafalan. Berikut penuturan Nesa siswa yang ditugasi murojaah pada Jumat, 29 November 2019:

"awalnya saya sib nggak mau mas. Tapi, karena ditunjuk langsung oleh ustaz, maka di rumah, saya minta Ibu membantu simaan mas. Jadi, sebelum tampil, saya disimak lebih dahulu sama Ibu, tepatnya murojaah juz 29. Alhamdulillah tadi sudah tampil walau masih ada yang keliru mas."20

Senada dengan kutipan di atas, Ust. Ponda menyebutkan bahwa kegiatan ini mendapat dukungan moril dan materil dari para orangtua siswa. seperti halnya snack kegiatan Jum'at murojaah, itu merupakan pemberian orangtua siswa untuk dikonsumsi bersama. Berikut kutipan wawancara dengan Ust. Ponda:

"Kegiatan ini kita adakan agar siswa berani tampil di depan umum. Salah dan kekeliruan bacaan itu biasa, sebab anak-anak ini masih tahap belajar, yang penting mereka pede dulu. Semangat menghafal mereka juga penting toh mas?. Syukurnya lagi,

18 Berdasarkan keterangan dari Ustaz Yuliadi Ponda ketika diwawancarai pada tanggal 29 November 2019, pukul 09.51 WIB.

19 Faizatul Mukholisoh, Anwar Sa'dullah, Nur Hasan, "Pelaksanaan Metode Muroja'ah Tahfidz Al-Qur'an di Ma'had Al-Ulya MAN Kota Baru” Vicratina: Jurnal Pendidikan Islam 4, no. 3 (2019): 191-196. http://www.riset.unisma.ac.id/index.php/fai/article/view/3314/2979.

20 Wawancara dengan Nesa Arini Arafah Siswa yang tampil murojaah pada tanggal 29 November 2019, membaca 6 surah dalam juz 29. Bertempat di Balai murojaah. 
orangtua juga support anak mereka di rumah, bahkan dukung kita para guru untuk intens membimbing anak mereka. Untuk menstimulus orangtua lainnya, saya juga share ke grup whatsapp wali siswa. intinya, saling memberi tahu perkembangan anak didik sebagai amanah dari Allah untuk kita."21

Mengomentari hal di atas, Tirtayani et.al. menyebutkan bahwa program kerjasama dengan melibatkan orangtua siswa adalah langkah baik. Sebab, pelibatan dan kerjasama antara pihak madrasah dan orangtua dapat menciptakan rasa memiliki program bersama, lebih memahami perkembangan anak, dan membantu komunikasi rumah-madrasah.22 Aspek ini tentu membantu perkembangan anak di usai sekolah dasar atau madrasah ibtidaiyah.

c. Istirahat dan Kudapan I-II

Pembelajaran di MI Nurul Ummah menggunakan sistem fullday. Untuk itu, pihak madrasah memberi waktu istirahat dan menyediakan kudapan bagi siswa. Hal ini diupayakan untuk memenuhi kebutuhan siswa, sehingga tidak hanya belajar "melulu", siswa juga diberi waktu istirahat cukup untuk mendukung proses tumbuhkembang.23 Hal ini dibenarkan pihak madrasah, bahkan istirahat dan kudapan ini diberikan agar antarsiswa saling menjalin silaturahmi dan menganggap teman layaknya saudara sendiri.24

Berkaitan dengan penyediaan kudapan, dipandang baik dan tepat oleh para orangtua/wali siswa. Hal ini seperti yang disampaikan Bu Luthfi berikut:

21 Wawancara dengan Ustaz Yuliadi Ponda (Koordinator Tahfiz dan Tahsin MI Nurul Ummah Kotagede Yogyakarta). Pada hari Jumat, 22 November 2019, pukul 07.44 WIB di Balai Murojaab MI Nurul Ummah.

22 Luh Ayu Tirtayani, Nice Maylani Asril, I Nyoman Wirya, Perkembangan Sosial Emosional pada Anak Usia Dini (Yogyakarta: Graha Ilmu, 2014), h. 51-52.

23 Nur Hidayah, "Layanan pada Anak Usia Dini (Studi Kasus di TPA Beringharjo Yogyakarta)" Dimensia 2, no. 1 (2008): 23-49. https://journal.uny.ac.id/index.php/dimensia/article/view/3397/2882. Lihat Ulfiani Rahman, "Karakteristik Perkembangan Anak Usia Dini” Lentera Pendidikan 12, no. 1 (2009): 46-57. https://doi.org/10.24252/lp.2009v12n1a4.

24 Berdasarkan keterangan dari Pak Adip Muammar Habibi, M.Pd., Kepala Madrasah (MI) Nurul Ummah Kotagede Yogyakarta. Pada hari Selasa, 01 Oktober 2019, pukul 08.30 WIB di Ruang Kepala Madrasah (MI) Nurul Ummah. 
“...di sini kan fullday mas, jadi tidak khawatir anakanak berkeliaran kemana-mana. Sebab, selalu dalam pengawasan pihak madrasah, makanan anak-anak juga kan dari internal, insyaAllah lebih aman. Bahkan, siang hari anak-anak juga ada waktu istirahat yang cukup mas. Intinya, senanglah mas lihat pengelolaannya."' 25

Istirahat dan kudapan menciptakan "madrasah rasa rumah" bagi siswa. Hal ini dipandang tepat dalam merekayasa suasana yang "nyaman" bagi siswa untuk belajar di lingkungan madrasah. Kemasan "unik" yang diprogramkan pihak madrasah ini, sejatinya menumbuhkan rasa kekeluargaan antarsiswa dengan "masakan 1 wajan yang sama" dan "tidur siang bersama".

Senada dengan hal di atas, Fatimah menerangkan, perkembangan biologis merupakan aspek penting bagi pendidikan anak. Hal ini semakin dipertegas dengan teknik dan langkah-langkah menghafal al-Qur'an dan belajar menulis, bahwa seorang pelajar membutuhkan istirahat di siang hari, sehingga memberikan waktu teramat penting bagi penyegaran kemampuan berpikir anak.26

Kebutuhan biologis anak dalam belajar, tentu menjadi aspek yang patut diperhatikan. Sebab, di dalam tubuh yang sehat, terdapat akal pikiran jernih lagi sehat.27 Dengan demikian, pengelolaan waktu istirahat siang bagi anak merupakan faktor pendukung belajar dan kesehatan, bahkan dapat disebut sebagai bentuk pengamalan hadis bagi anak sejak usia dasar dalam memenuhi aspek biologisnya.

25 Wawancara dengan Bu Luthfi Layli Nur Afita (Wali siswa MI Nurul Ummah Kotagede Yogyakarta/Ibunya Gibran Siswa kelas II-B). Pada hari Jumat, 30 Juni 2019, pukul 07.55 WIB di depan Ruang Kelas I A.

26 Fatimah Zam Zam Mg, "Metode Pendidikan Islam Perspektif Hadis Rasulullah saw." Sabilarrasyad 2, no. 2, (2017): 70-79. http://jurnal.dharmawangsa.ac.id/index.php/sabilarrasyad/article/view/127.

Lihat pula Ranti Safi'ah \& Marhumah, "Pendidikan Karakter Mandiri Siswa MI Baiquniyyah dan Anak Binaan RSB Diponegoro" Abdau: Jurnal Pendidikan Madrasah Ibtidaiyah 1, no. 2 (2018). http://jurnal.stpibim.ac.id/index.php/ABDAU/article/view/13.

27 Depi Yanti, "Konsep Akal dalam Perspektif Harun Nasution" Jurnal Intelektualita: Keislaman, Sosial, dan Sains 6, no. 1 (2017): 51-62. https://doi.org/10.19109/intelektualita.v6i1.1300. 
Berkaitan dengan di atas, Fitriah menyebutkan bahwa kudapan dan penyediaan makanan yang dikelola langsung oleh pihak sekolah/madrasah merupakan bentuk pengamalan hadis kebersihan dan pemeliharaan anak di lingkungan belajarnya.28

Dengan demikian, dipahami bahwa istirahat dan kudapan I-II memiliki andil penting bagi kebutuhan biologis anak. Lebih dari itu, keduanya juga merupakan bentuk pengamalan hadis yang dibiasakan sejak dasar kepada anak, dalam membantu pertumbuhan, perkembangan, dan kemampuan belajar anak.

d. Semester Swim

Semester swim merupakan rutinitas madrasah yang dilaksanakan setiap 6 (enam) bulan sekali. Kegiatan ini ditujukan sebagai bentuk relaksasi bagi siswa setiap akhir semester. Senada dengan ini, kepala madrasah menuturkan bahwa sebelum ujian akhir semester, siswa diajak ke kolam renang untuk relaksasi pra-ujian dan terpenting melalui kegiatan ini siswa diharapkan dapat semakin akrab.29

Berkaitan dengan renang, Febrianta menyebutkan bahwa renang dapat membantu peningkatan IQ, daya tahan tubuh, mempercepat pertumbuhan, melatih keseimbangan, stimulasi motorik, serta melatih rasa percaya diri dan keberanian siswa.30 Senada dengan ini, Mardliyah et.al. menambahkan bahwa renang dapat menambahkan konsentrasi belajar siswa.31 Sehingga, kegiatan renang bermanfaat bagi siswa secara fisik-motorik dan memfasilitasi siswa untuk menjalin persaudaraan sebagai alternatif membantuk perkembangan sosial-emosional siswa.

28 Mia Fitriah, "Kajian Al-Qur'an dan Hadits tentang Kesehatan Jasmani dan Ruhani” Tajdid: Jurnal Ilmu Ushuluddin 15, no. 1 (2016). https://doi.org/10.30631/tjd.v15i1.29. Lihat pula Jazariyah, "Internalisasi Nilainilai Hadits Kebersihan dalam Pendidikan Anak Usia Dini” Masile: Jurnal Studi $\begin{array}{lllll}\text { Ilmu Keislaman } & 1, & \text { no. } & 1 & \text { (2019). }\end{array}$ http://jurnal.staima.ac.id/index.php/masile/article/view/9.

29 Wawancara dengan Pak Adip Muammar Habibi, M.Pd., Kepala Madrasah (MI) Nurul Ummah Kotagede Yogyakarta. Pada hari Selasa, 01 Oktober 2019, pukul 08.30 WIB di Ruang Kepala Madrasah (MI) Nurul Ummah.

30 Yudha Febrianta, "Alternatif Mengembangkan Kemampuan Motorik Kasar Anak Usia Dini dengan Aktivitas Akuatik (Berenang)" Al-Athfal: Jurnal Pendidikan Anak Usia Dini 2, no. 2 (2016): 85-96. http://ejournal.uinsuka.ac.id/tarbiyah/index.php/alathfal/article/view/1269/1152.

31 Ainul Mardliyah, Susiana Candrawati, Dewi Nilamsari, "Hubungan Renang dengan Konsentrasi pada Anak" Mandala of Health 8, no. 3 (2015): 602611. http://jos.unsoed.ac.id/index.php/mandala/article/view/348. 
Berenang juga merupakan olahraga yang dianjurkan Nabi saw. kepada umatnya. Hal ini dimaksudkan sebagai upaya melatih mental anak sejak usia dasar.32 Senada dengan ini, Rusli menegaskan bahwa berenang merupakan anjuran Nabi saw. kepada umatnya sejak masa anak-anak, sebab bermanfaat bagi kekuatan fisik dan daya tahan anak.33 Kestabilan anak dalam fase pertumbuhan dan perkembangan ini memiliki implikasi kepada pencapaian aspek kecerdasan belajar anak, baik itu kecerdasan intelektual, emosional dan spiritual.

Dengan demikian, dipahami bahwa kegiatan berenang (semester swim) yang diterapkan oleh MI Nurul Ummah merupakan bentuk pengamalan hadis (living hadis) kepada anak sejak usia dasar. Pemograman kegiatan ini juga bermanfaat bagi kebutuhan biologis anak, ketahanan dan kekuatan fisik, serta berimplikasi kepada peningkatan kemampuan belajar anak.

\section{e. Hadroh van Beethoven}

Hadroh merupakan kesenian (seni musik) yang lazim dimainkan oleh siswa MI Nurul Ummah.34 Kesenian ini seperti "tak kenal waktu", sebab Yuda menerangkan bahwa badrob ini terjadwal di madrasah, begitupun para siswa seringkali mengisi waktu istirahat dengan bermain-main, salah satunya yang "tak ketinggalan" ialah badroh. 35

Tinjauan aspek historis, diketahui bahwa hadroh merupakan kesenian yang men-tradisi di kalangan umat Islam.36

32 Wardatul Asfiyah \& Lailul Ilham, "Urgensi Pendidikan Keluarga dalam Perspektif Hadits dan Psikologi Perkembangan” Hisbab: Jurnal Bimbingan Konseling dan Dakwah Islam 16, no. 1 (2019). https://doi.org/10.14421/hisbah.2019.161-01.

33 Rahmatullah Rusli, "Klasifikasi Pendidikan dalam Sudut Pandang Hadis Nabi” Jurnal Pendidikan Islam 8, no. 1 (2017). https://journal.uhamka.ac.id/index.php/ipi/article/view/300.

34 Setiap berkunjung ke MI Nurul Ummah, "dapat dipastikan" mendengar pukulan rebana khas para siswa di sela-sela jam belajar (waktu istirahat). Padahal kegiatan hadroh sendiri dijadwalkan setiap sore mulai jam 14.00 WIB hingga tiba waktu Asar.

35 Wawancara dengan Pak Yuda (Wakil Kepala Madrasah bidang Kesiswaan MI Nurul Ummah Kotagede Yogyakarta) pada 16 Desember 2019, pukul 12.00 WIB di ruang guru.

36 Muhamad Mukhlason, "Pengembangan Kurikulum Muatan Lokal Seni Hadroh Pasuruan" Jurnal Studi Islam 10, no. 2 (2015): 128-142. http://ejournal.kopertais4.or.id/mataraman/index.php/tahdzib/article/view/220 $2 / 2393$. 
Sebab, selain diiringi pukulan rebana, hadroh juga bermuatan lirik-lirik yang bernuansa Islami dan salawat kepada Nabi saw. Kegiatan ini juga dipandang dapat menstimulus kesadaran dan kecintaan siswa akan seni musik "daerah" dan kearifan lokal.37 Bahkan, lebih lanjut secara filosofis kesenian ini menumbuhkan "gairah" tersendiri bagi siswa untuk mencintai Islam melalui akulturasi budaya dengan ajaran Islam itu sendiri.

f. Yearly Haflah Khotmil Qur'an

Haflah merupakan kegiatan tahunan madrasah untuk pengumuman kelulusan tahfiz dan tahsin siswa. Hal ini seperti yang dilakukan pihak madrasah pada 2017 lalu. Pihak madrasah mewisuda 7 (tujuh) siswa yang telah mencapai target hafalan 3 (tiga) juz. Berikut tertera nama-nama siswa tersebut.

Tabel 2. Wisudawan/wati Al-Qur'an 3 Juz bi al-Hifdzi MI Nurul Ummah Kotagede Yogyakarta

\begin{tabular}{cll}
\hline No. & \multicolumn{1}{c}{ Nama } & \multicolumn{1}{c}{ Tempat Tanggal Lahir } \\
\hline 1. & Queen Aisha Permata Ahimsa & Yogyakarta, 05 April 2009 \\
\hline 2. & Nathaniela Nabila Alifa & Yogyakarta, 07 November 2008 \\
\hline 3. & Diana Putri Aulia Al-Junaid & Yogyakarta, 12 Oktober 2008 \\
\hline 4. & Zenopati Rahul Qisthy Romadony & Yogyakarta, 15 September 2008 \\
\hline 5. & Muhammad Rian Syafaat & Yogyakarta, 04 April 2008 \\
\hline 6. & Ahmad Zidni Alfa Nashrin & Bantul, 23 Oktober 2009 \\
\hline 7. & Aditya Firmansyah & Tangerang, 20 September 2008 \\
\hline
\end{tabular}

Sumber: Bagian Tata Usaha MI Nurul Ummah.

Kegiatan ini diinisasi sebagai bentuk apresiasi kepada siswa yang telah mencapai target hafalan. Senada dengan ini, Ulwiyah mengemukakan bahwa apresiasi menciptakan ikatan stimulus-respons bagi anak untuk meningkatkan belajar.38 Hal ini mematrikan persepsi pada anak, bahwa kegiatan positif yang dilakukan memperoleh dukungan dari lingkungan sekitar tempat siswa belajar, terutama belajar dan mengamalkan al-Qur'an.

Ditinjau dari aspek oral/recitation, kegiatan murojaah, "setoran bacaan dan hafalan", serta siswa mengikuti bacaan yang diucapkan oleh guru.39 Metode mengulang bacaan melalui

37 Seni daerah yang telah diakulturasikan dengan nilai-nilai Islami, meliputi pelaksanaan, bacaan yang dilafalkan (salawat) dan pakaian yang dikenakan.

38 Nur Ulwiyah, "Landasan Psikologi dan Aktualisasinya dalam Pendidikan Islam" Religi: Jurnal Studi Islam 6, no. 1 (2015): 76-99. https://journal.unipdu.ac.id/index.php/religi/article/view/562/495.

39 Observasi di MI Nurul Ummah Kotagede Yogyakarta pada tanggal 5 November 2019, pukul 10.15 WIB. 
kegiatan murojaah ini dipandang tepat dalam membantu siswa menghafal dan menghayati setiap materi yang diajarkan.

Aspek aural/hearing dalam rutinitas madrasah ditunjukkan melalui proses simaan ketika tahsin dan tahfiz alQur'an, hadroh dan haflah al-Qur'an setiap tahun. Begitupun, aspek selanjutnya berupa writing/tulisan belum terkonsep dan teraplikasikan secara matang di MI Nurul Ummah. Hal ini diakui pihak madrasah didasari keterbatasan sarana prasarana madrasah yang masih tergolong "baru".40

Adapun aspek attitude/sikap ditampilkan dalam keseharian siswa mempraktikkan gemar baca dan hafal alQur'an, saling menjalin persaudaraan dengan teman sebaya melalui kegiatan istirahat bersama dan kudapan, serta siswa juga difasilitasi relaksasi untuk menjalin keakraban tiap semester berupa semester swim. Berdasarkan uraian tersebut, dapat disimpulkan bahwa bentuk living Qur'an dan hadis di MI Nurul ditunjukkan dalam rutinitas madrasah.

\section{Living Qur'an dan Hadis Melalui Ritual Ibadah}

a. Pembacaan Asmaul Husna

Kegiatan ini merupakan kegiatan pertama dari seluruh rangkaian pembelajaran di MI Nurul Ummah. Hal ini diakui pihak madrasah tepat diterapkan untuk setiap mengawali pagi, selain membiasakan siswa mengulang-ulang bacaan yang baik berupa asmaul husna, juga dipandang dapat membawa berkah bagi lembaga dan siswa.41

Senada dengan itu, Rahman berpendapat bahwa asmaul husna merupakan sumber segala ciptaan dan urusan yang terkandung dalam nama-nama baik Allah. Sehingga tepat dibiasakan bagi siswa, karena di dalamnya terdapat kebutuhan fitrah manusia akan kasih sayang, sikap jujur, inovatif.42

40 Berdasarkan keterangan dari Pak Adip Muammar Habibi, M.Pd., Kepala Madrasah (MI) Nurul Ummah Kotagede Yogyakarta. Pada hari Selasa, 16 Desember 2019, pukul 14.11 WIB di Ruang Kepala Madrasah (MI) Nurul Ummah.

41 Lili Khoirunnisa. "Hubungan antara Kebiasaan Membaca Asmaul Husna dengan Kecerdasan emosional Siswa Kelas XI MA Nurul Ummah Yogyakarta".Jurnal Pendidikan Agama Islam 14, no. 1 (2017): 51-68. https://dx.doi.org/10.14421/ipai.2017.141-04.

42 Abd. Rahman R, "Memahami Esensi Asmaul Husna dalam AlQur'an (Implementasinya sebagai Ibadah dalam Kehidupan)" Jurnal Adabiyab 11, 
Bahkan, ditinjau dari sisi teologis, pelafalan asmaul husna mengandung upaya mengimani Allah swt. melalui sifatsifatNya.43

b. Salat Duha, Zuhur dan Asar Berjamaah

Salat Duha, Zuhur dan Asar dilaksanakan secara berjamaah di MI Nurul Ummah, tepatnya di Masjid Al-Faruq.44 Salat Duha diimami langsung oleh siswa kelas IV-V 45 dengan bacaan zahar sebagai upaya latihan bagi seluruh siswa.46 Senada dengan ini, Ust. Ponda menuturkan:

"Untuk salat Duha, siswa sengaja dilatih bacaannya secara zahar mas agar siswa hafal bacaan salat dengan baik. Imamnya juga dipilih dari siswa, dengan tujuan melatih mental siswa jadi imam salat, agar benih keberanian itu terpatri sejak kecil mas."47

Pembiasaan ini penting dilaksanakan agar secara perlahan terpatri dan menjadi karakter siswa MI Nurul Ummah. Sebab, anak usia MI kerap kali memandang bahwa lingkungan sekitarnya adalah "wahana" bermain.48 Untuk itu, anak butuh pembiasaan dan pengawasan dalam proses pendidikan. 49

Adapun salat Zuhur dan Asar dilaksanakan secara berjamaah dengan para santri Pondok Pesantren Nurul Ummah.

no. alauddin.ac.id/index.php/adabiyah/article/view/1723/pdf.

150-166. http://journal.uin-

43 Alfauzan Amin, "Pemahaman Konsep Abstrak Ajaran Agama Islam pada Anak Melalui Pendekatan Sinektik dan Isyarat Analogi dalam Alquran" Madania 21, no. 2 (2017): 157-170. https://ejournal.iainbengkulu.ac.id/index.php/madania/article/view/608/pdf.

44 Masjid Al-Faruq ialah nama masjid di Pondok Pesantren Nurul Ummah Kotagede Yogyakarta.

45 Observasi di MI Nurul Ummah Kotagede Yogyakarta pada tanggal 17 Oktober 2019, pukul 07.15 WIB.

46 Berdasarkan keterangan dari Ustaz Rohman, ketika diwawancarai di Masjid Al-Faruq pada tanggal 17 Oktober 2019, pukul 10.08 WIB.

47 Wawancara dengan Ustaz Yuliadi Ponda (Koordinator Tahfiz dan Tahsin MI Nurul Ummah Kotagede Yogyakarta). Pada Pada hari Selasa, 01 Oktober 2019, pukul 07.15 WIB di Masjid Al-Faruq.

48 Abdul Khobir, "Upaya Mendidik Anak Melalui Permainan Edukatif" Forum Tarbiyah 7, no. 2 (2013). http://ejournal.iainpekalongan.ac.id/index.php/forumtarbiyah/article/view/262.

49 Abdullah Nashih Ulwan, Pendidikan Anak Menurut Islam: Kaidah-kaidah Dasar, terj. Khalilullah Ahmas Masjkur Hakim, (Bandung: PT Remaja Rosdakarya, 1992), h. 59. 
Sehingga, pembiasaan disiplin waktu salat yang diajarkan melalui salat berjamaah menjadi modal dan bekal baik bagi siswa MI Nurul Ummah sejak usia dasar. Di samping itu, siswa juga terbiasa menjalin persaudaraan (ukbuwab) melalui kegiatan terprogram yang dilaksanakan secara bersama-sama di madrasah.

c. Salawat dan Zikir Bersama Usai Duha

Salawat dan Zikir bersama usai Duha merupakan ritual ibadah yang diprogramkan oleh pihak madrasah (MI Nurul Ummah). Kegiatan ini ditujukan sebagai bentuk pengamalan ibadah dan tazkiyah an-Nafs. Sehingga, siswa memperoleh kemudahan dalam menerima, menghayati dan menghafal alQur'an.50

Senada dengan itu, A'yuni mengemukakan bahwa salawat merupakan ibadah yang "ringan" diucapkan, namun besar pahala yang diperoleh.51 Bahkan Allah dalam al-Qur'an memuliakan orang-orang yang bersalawat.52 Sehingga, kegiatan ini dipandang tepat sebagai bentuk kontekstualisasi al-Qur'an sejak usia dasar bagi siswa.

Ditinjau dari aspek oral/ recitation, kegiatan salawat, zikir, dan pembacaan asmaul husna, serta bacaan zabar siswa ketika salat Duha berjamaah dipandang tepat dalam membantu siswa menghayati keagamaan dengan mengamalkan nilai Qur'ani dan sunnah Nabi saw.

Aspek aural/ hearing dalam ritual ibadah ditunjukkan melalui saling menyimak bacaan salat Duha dan salawatan bersama siswa. Begitupun, aspek selanjutnya berupa writing/tulisan ditampilkan melalui tulisan asmaul husna yang terpajang besar di dinding halaman madrasah.

Adapun aspek attitude/sikap ditampilkan dalam keseharian siswa mempraktikkan aktif salat berjamaah, terbiasa membaca asmaul husna setiap pagi dan salawat serta zikir usai Duha. Berdasarkan uraian tersebut, dapat disimpulkan bahwa bentuk living

50 Berdasarkan keterangan dari Ustaz Rohman, ketika diwawancarai di Masjid Al-Faruq pada tanggal 17 Oktober 2019, pukul 10.08 WIB.

51 Qurrata A'yuni, "Salawat kepada Nabi dalam Perspektif Hadis" Substantia 18, no. 2 (2016): 165-182. https://jurnal.arraniry.ac.id/index.php/substantia/article/view/3003/2147.

52 Abdul Aziz al-Syanawi, Keutamaan Salawat dan Fadbilah Amal, terj. Anshori Umar Sitanggal (Jakarta: Pustaka al-Kautsar, 2005), h. 3. 
Qur'an dan hadis di MI Nurul ditunjukkan dalam aspek ritual ibadah.

\section{Living Qur'an dan Hadis Melalui Pembinaan Akhlak}

a. Nasihat Pagi

Nasihat pagi merupakan salah satu kegiatan pembinaan akhlak di MI Nurul Ummah. kegiatan ini dilaksanakan usai salat Duha berjamaah. Guru setiap pagi memberikan nasihat kepada siswa dengan menyesuaikan usia siswa. Seperti kutipan nasihat pagi yang disampaikan oleh Ust. Rohman berikut:

"anak-anakku, kalau sudah di MINU ini sing serius belajarnya, semangat, jaga kebersihan, hormat sama yang tua, sayang sama yang muda, pokoke manut penak (PMP). Ora manut ora kepenak dan itu jeneng e durhaka kearo guru dan ustaz." 53

Senada dengan itu, Ulwan menegaskan bahwa metode nasihat merupakan cara tepat dalam mendidikkan keimanan, moralitas, dan sikap sosial anak sesuai anjuran Islam.54 Bukankah ahli hikmah yang namanya disebutkan dalam alQur'an juga mendidik anaknya dengan metode nasihat?55

Lebih lanjut, nasihat juga merupakan anjuran Islam bagi setiap penganutnya dalam kebenaran dan kesabaran.56 Untuk itu, pembinaan akhlak melalui nasihat pagi ini tepat diterapkan sebagai aktualisasi nilai-nilai anjuran Islam dalam mendidik anak yang termaktub dalam al-Qur'an dan hadis.

1. Paguyuban Wali Siswa dengan Pihak Madrasah

Paguyuban merupakan bentuk persatuan yang didasari persamaan antar-individu, lantas membentuk wadah atau

53 Nasihat pagi yang disampaikan Ustadz Rohman kepada siswa MI Nurul Ummah pada tanggal 17 Oktober 2019, pukul 07.44 WIB di Masjid AlFaruq.

54 Abdullah Nashih Ulwan, Pendidikan Anak Menurut Islam: Kaidah-kaidah Dasar, terj. Khalilullah Ahmas Masjkur Hakim, (Bandung: PT Remaja Rosdakarya, 1992), h. 65-68.

55 Ahmad Atabik dan Ahmad Burhanuddin, "Konsep Nasih Ulwan tentang Pendidikan Anak" Elementary 3, no. 2 (2015): 274-296. file:///C:/Windows/system32/config/systemprofile/Downloads/1454-4859-1SM.pdf. Lihat Al-Qur'an al-Karim. Al-Qur'an Terjemah Dan Asbabun Nuzul: AlMalik (The Brave) (Surakarta: CV. Al-Hanan, 2009), h. 412.

56 Al-Qur'an al-Karim. Al-Qur'an Terjemah Dan Asbabun Nuzul: Al-Malik (The Brave) (Surakarta: CV. Al-Hanan, 2009), h. 601. 
organisasi atas kesamaan secara alamiah tersebut.57 Didasari hal ini, MI Nurul Ummah atas kesadaran lembaga mewujudkan persatuan berwujud paguyuban untuk meneguhkan persamaan yang terjalin dalam satu tujuan bersama mendidik anak.

Berdasarkan penuturan kepala madrasah, bahwa hampir seluruh elemen madrasah adalah alumni Pondok Pesantren Nurul Ummah, mulai dari guru, tenaga kependidikan MI Nurul Ummah, hingga wali siswa.58 Atas dasar ini, kegiatan paguyuban diinisiasi oleh pihak madrasah dengan mengadakan pertemuan bersama wali siswa setiap 2 (dua) bulan sekali dan membentuk grup Whatsapp (antara wali kelas dengan wali siswa).59

Tirtayani et.al. menyebut upaya ini sebagai bentuk harmonisasi rumah-madrasah.60 Di samping itu, siswa juga kerapkali diikutsertakan sebagai "bentuk keteladanan" agar guyub dan rukun dengan teman sebaya, layaknya guru (wali kelas) dengan orangtua (wali) siswa.61

Uraian di atas menjelaskan bahwa kegiatan paguyuban ditujukan untuk membahas perkembangan siswa MI Nurul Ummah. Lebih utama, kegiatan ini ditujukan sebagai bentuk meneladankan pada siswa untuk guyub dan berdampingan dengan teman layaknya saudara. Sehingga, upaya meneladankan ini menjadi kontekstualisasi ajaran dalam al-Qur'an dan hadis kepada siswa sejak dasar.

2. Jumat Bersih

Jumat bersih merupakan agenda pembinaan akhlak siswa untuk praktik kebersihan bersama pihak guru. Kegiatan ini diinisiasi pihak madrasah sebagai proses pembiasaan sikap

57 Soerjono Soekanto. Teori Sosiologi tentang Pribadi Masyarakat (Jakarta: Ghalia Indonesia, 1982).

58 Berdasarkan keterangan dari Adip Muammar Habibi, M.Pd., Kepala Madrasah (MI) Nurul Ummah Kotagede Yogyakarta. Pada hari Selasa, 16 Desember 2019, pukul 14.11 WIB di Ruang Kepala Madrasah (MI) Nurul Ummah.

59 Grup whatsapp ini diperuntukkan bagi wali siswa dengan wali kelas bersangkutan. Seperti grup wali siswa kelas 2 A secara menyeluruh wali siswa masuk grup tersebut dan wali kelas 2 A tersebut. Begitu juga dengan kelas lainnya dari kelas 1-5 MI Nurul Ummah.

60 Luh Ayu Tirtayani, Nice Maylani Asril, I Nyoman Wirya, Perkembangan Sosial Emosional pada Anak Usia Dini (Yogyakarta: Graha Ilmu, 2014), h. 51.

61 Wawancara dengan Pak Riski, Wali kelas 3 MI Nurul Ummah Kotagede Yogyakarta. Pada hari Selasa, 26 November 2019, pukul 10.30 WIB di Kantor Pondok Pesantren Nurul Ummah. 
bersih pada siswa serta keteladanan dengan melibatkan guru madrasah.

Ditinjau dari aspek psikologis, kegiatan ini dapat melatih anak sadar kebersihan, mulai dari cara memelihara kebersihan hingga dampak dari hidup bersih. Lebih lanjut, kegiatan ini merupakan wujud manifestasi iman kepada Allah swt.62 Bahkan, jelas dalam al-Qur'an bahwa Allah menyukai orangorang yang bersih.63

Mendukung kegiatan tersebut, pihak madrasah mengadakan penilaian tiap bulan untuk menetapkan kelas terbersih.64 Hal ini ditujukan sebagai upaya menstimulus siswa untuk terbiasa serta termotivasi mencintai kebersihan. Pada gilirannya, siswa dapat tergerak secara mandiri dan inisiatif sendiri membersihkan kelas, madrasah, dan juga rumah.

Ditinjau dari aspek oral/ recitation, kegiatan nasihat pagi dipandang tepat dalam membantu siswa menghayati keagamaan dengan mengamalkan nilai Qur'ani dan sunnah Nabi saw. Aspek aural/hearing dalam pembinaan akhlak ditunjukkan melalui kegiatan mendengarkan nasihat dari guru setiap pagi. Begitupun, aspek selanjutnya berupa writing/tulisan belum didukung dengan tempelan atau pajangan hadis dan ayat al-Qur'an terkait pembinaan akhlak siswa di madrasah.

Adapun aspek attitude/sikap ditampilkan dalam keseharian siswa mempraktikkan cinta kebersihan lingkungan madrasah dan guyub antar-siswa melalui keteladanan kegiatan paguyuban wali siswa dengan pihak madrasah setiap dua bulan sekali. Berdasarkan uraian tersebut, dapat disimpulkan bahwa bentuk living Qur'an dan hadis di MI Nurul ditunjukkan dalam aspek pembinaan akhlak.

62 Sesuai dengan materi yang diajarkan kepada siswa kelas I MI dalam mata pelajaran al-Qur'an hadis, tema "Aku Cinta Kebersihan". Lihat Chairul Fata, Cinta Al-Qur'an dan Hadis 1 untuk Kelas I Madrasah Ibtidaiyah, Editor: Rofiqoh, (Solo: PT Tiga Serangkai Pustaka Mandiri, 2018), h. 4-120.

63 Al-Qur'an al-Karim. Al-Qur'an Terjemah Dan Asbabun Nuqul: Al-Malik (The Brave) (Surakarta: CV. Al-Hanan, 2009), h. 204.

64 Berdasarkan keterangan dari Yuda Pak Yuda (Wakil Kepala Madrasah Bidang Kesiswaan MI Nurul Ummah Kotagede Yogyakarta) dan para siswa usai Jumat bersih di lingkungan madrasah pada tanggal 25 Oktober 2019. 


\section{PENUTUP}

Hasil penelitian ini menunjukkan bahwa aktivitas sosial di madrasah mengindikasikan terwujud upaya living Qur'an dan hadis. Hal ini dipraktikkan melalui kegiatan terprogram madrasah yakni, rutinitas madrasah, ritual ibadah dan pembinaan akhlak. Sehingga, menjadi landasan dasar pembiasaan dan pembentukan karakter sebagai pengamalan nilai-nilai Qur'ani dan hadis yang dipelajari siswa sehari-hari. Fokus kegiatan tersebut, ditinjau dari aspek oral, aural, writing, dan attitude. Sehingga, terpenuhi empat aspek sesuatu disebut sebagai upaya living Qur'an dan hadis.

\section{DAFTAR PUSTAKA}

Aini, Siti Qurrotul, “Tradisi Qunut dalam Shalat Maghrib di Pondok Pesantren Wahid Hasyim Yogyakarta (Studi Living Hadis)" Jurnal Living Hadis, vol. 1, no. 2, 2016, pp. 227-241, http://ejournal.uinsuka.ac.id/ushuluddin/Living/article/view/1120/1022.

al-Karim, Al-Qur'an, Al-Qur'an Terjemah Dan Asbabun Nuzul: AlMalik (The Brave), Surakarta: CV. Al-Hanan, 2009.

al-Syanawi, Abdul Aziz, Keutamaan Salawat dan Fadbilah Amal, terj. Anshori Umar Sitanggal, Jakarta: Pustaka al-Kautsar, 2005.

Amin, Alfauzan, "Pemahaman Konsep Abstrak Ajaran Agama Islam pada Anak Melalui Pendekatan Sinektik dan Isyarat Analogi dalam Alquran" Madania 21, no. 2, 2017, pp. 157170.

https://ejournal.iainbengkulu.ac.id/index.php/madania/arti cle/view/608/pdf.

Amin, Wildan Rijal, "Living Hadis dalam Fenomena Tradisi Kupatan di Desa Durenan Kecamatan Durenan Kabupaten Trenggalek" Tesis, Yogyakarta: Pascasarjana UIN Sunan Kalijaga, 2017.

Angelia, Yeni dan In'amul Hasan, "Merantau dalam Menuntut Ilmu (Studi Living Hadis oleh Masyarakat Minangkabau)" Jurnal Living Hadis, vol. 2, no. 1, 2017, pp. 67-82, http://ejournal.uinsuka.ac.id/ushuluddin/Living/article/view/1316/1190.

Arif, Mahmud, "Al-Qur'an As an 'Open Book' in Educational Perspective: The Significant Meaning of Pedagogical Values and Productive Reading" Sunan Kalijaga International Journal on Islamic Educational Research, vol. 3, no. 2, 2019, pp. 1-16. 
http://ejournal.uin-

suka.ac.id/tarbiyah/index.php/SKIJIER/article/view/2811. Assingkily, Muhammad Shaleh, "Living Qur'an as A Model of Islamic Basic Education in the Industrial Era 4.0" Al-Ibtida': Jurnal Pendidikan Guru MI, vol. 6, no. 1, 2019, pp. 19-36, http://dx.doi.org/10.24235/al.ibtida.snj.v6i1.3876.

Atabik, Ahmad dan Ahmad Burhanuddin, "Konsep Nasih Ulwan tentang Pendidikan Anak" Elementary 3, no. 2, 2015, pp. 274296.

file:///C:/Windows/system32/config/systemprofile/Dow nloads/1454-4859-1-SM.pdf.

Atabik, Ahmad, "The Living Qur'an: Potret Budaya Tabfiz Al-Qur'an di Nusantara" Jurnal Penelitian, vol. 8, no. 1, 2014, pp. 161 178 ,

http://journal.stainkudus.ac.id/index.php/jurnalPenelitian/ article/download/1346/1190.

A'yuni, Qurrata, "Salawat kepada Nabi dalam Perspektif Hadis" Substantia 18, no. 2, 2016, pp. 165-182. https://jurnal.arraniry.ac.id/index.php/substantia/article/view/3003/2147.

Basri, Lukman, "Pemahaman dan Pengamalan Santri Pon-Pes IMMIM Terhadap Mukhtar Al-Ahadis" Jurnal Kajian Ilmu Hadis, vol. 8, no. 2, 2017, pp. 192-222, http://journal.uinalauddin.ac.id/index.php/tahdis/article/view/7228/5933.

Budianto, Nanang, "Implementasi Pengembangan Madrasah dan Sekolah Islam Unggulan sebagai Upaya Peningkatan Kualitas Pendidikan Islam" FALASIFA: Jurnal Studi Keislaman, vol. 8, no. 1, 2017, pp. 109-126. http://ejournal.inaifas.ac.id/index.php/falasifa/article/view $\angle 42$.

Fadlillah, Annisa, "Pembacaan Surat Al-Insyirah dan Al-Qodr pada Tradisi Bayen: Studi Living Qur'an pada Masyarakat Wonokerto Kabupaten Semarang" Tesis, Yogyakarta: Pascasarjana UIN Sunan Kalijaga, 2018.

Fauziyah, Nimatul, "Faktor Penyebab Kejenuhan Belajar Sejarah Kebudayaan Islam (SKI) pada Siswa Kelas XI Jurusan Keagamaan di MAN Tempel Sleman" Jurnal Pendidikan Agama Islam, vol. 14, no. 1, 2017: 99-108.

Febrianta, Yudha, "Alternatif Mengembangkan Kemampuan Motorik Kasar Anak Usia Dini dengan Aktivitas Akuatik (Berenang)" Al-Athfal: Jurnal Pendidikan Anak Usia Dini 2, no. 2, 2016, pp. 85-96. http://ejournal.uin- 
suka.ac.id/tarbiyah/index.php/alathfal/article/view/1269/1 152.

Fitriah, Mia, "Kajian Al-Qur'an dan Hadits tentang Kesehatan Jasmani dan Ruhani" Tajdid: Jurnal Ilmu Usbuluddin 15, no. 1, 2016. https://doi.org/10.30631/tjd.v15i1.29.

Hidayat, Muhtar S., "Pendekatan Kontekstual dalam Pembelajaran" Insania: Jurnal Pemikiran Alternatif Kependidikan, vol. 17, no. 2, 2012.

http://ejournal.iainpurwokerto.ac.id/index.php/insania/arti cle/view/1500.

Hidayah, Nur, "Layanan pada Anak Usia Dini (Studi Kasus di TPA Beringharjo Yogyakarta)" Dimensia 2, no. 1, 2008, pp. 23-49. https://journal.uny.ac.id/index.php/dimensia/article/view/ $3397 / 2882$.

Iballa, Dona Kahfi. MA., "Tradisi Mandi Balimau di Masyarakat Kuntu: Living Hadis Sebagai Bukti Sejarah" Jurnal Living Hadis, vol. 1, no. 2, 2016, pp. 275-293, http://ejournal.uinsuka.ac.id/ushuluddin/Living/article/view/1122/1024

Jazariyah, "Internalisasi Nilai-nilai Hadits Kebersihan dalam Pendidikan Anak Usia Dini" Masile: Jurnal Studi Imu Keislaman 1, no. 2019. http://jurnal.staima.ac.id/index.php/masile/article/view/9.

Khobir, Abdul, "Upaya Mendidik Anak Melalui Permainan Edukatif" Forum Tarbiyah 7, no. 2, 2013. http://ejournal.iainpekalongan.ac.id/index.php/forumtarbiyah/artic le/view/262.

Khoirunnisa, Lili, "Hubungan antara Kebiasaan Membaca Asmaul Husna dengan Kecerdasan emosional Siswa Kelas XI MA Nurul Ummah Yogyakarta".Jurnal Pendidikan Agama Islam 14, no. 1, 2017, pp. 51-68. https://dx.doi.org/10.14421/jpai.2017.141-04.

Khosyiah, Faiqatul, "Living Hadis dalam Kegiatan Peringatan Maulid Nabi di Pesantren Sunan Ampel Jombang" Jurnal Living Hadis, vol. 3, no. 1, 2018, pp. 23-45, http://ejournal.uinsuka.ac.id/ushuluddin/Living/article/view/1363/1316.

Kristin, Firosalia, "Efektivitas Model Pembelajaran Kooperatif Tipe STAD Ditinjau dari Hasil Belajar IPS Siswa Kelas 4 SD" Scholaria: Jurnal Pendidikan dan Kebudayaan, vol. 6, no. 2, 2016: 74-79. https://doi.org/10.24246/j.scholaria.2016.v6.i2.p74$\underline{79}$. 
Kosim, Muhammad, "Madrasah di Indonesia (Pertumbuhan dan Perkembangan)" Tadris: Jurnal Pendidikan Islam, vol. 2, no. 1, 2007, pp. 41-57. http://ejournal.stainpamekasan.ac.id/tadris/article/view/20 $\underline{9}$.

Mardliyah, Ainul, et.al., "Hubungan Renang dengan Konsentrasi pada Anak" Mandala of Health 8, no. 3, 2015, pp. 602-611. http://jos.unsoed.ac.id/index.php/mandala/article/view/3 $\underline{48}$.

Mg, Fatimah Zam Zam, "Metode Pendidikan Islam Perspektif Hadis Rasulullah saw." Sabilarrasyad 2, no. 2, 2017, pp. 7079.

http://jurnal.dharmawangsa.ac.id/index.php/sabilarrasyad/ article/view/127.

Muhtador, Moh., "Pemaknaan Ayat Al-Qur'an dalam Mujahadah: Studi Living Qur'an di PP Al-Munawwir Krapyak Komplek Al-Kandiyas" Jurnal Penelitian, vol. 8, no. 1, 2014, pp. 93-112, http://journal.stainkudus.ac.id/index.php/jurnalPenelitian/ article/download/1343/1187.

Mukholisoh, Faizatul, et.al., "Pelaksanaan Metode Muroja'ah Tahfidz Al-Qur'an di Ma'had Al-Ulya MAN Kota Baru" Vicratina: Jurnal Pendidikan Islam 4, no. 3, 2019: 191-196. http://www.riset.unisma.ac.id/index.php/fai/article/view/ 3314/2979.

Mukhlason, Muhamad, "Pengembangan Kurikulum Muatan Lokal Seni Hadroh Pasuruan" Jurnal Studi Islam 10, no. 2, 2015, pp. 128-142.

http://ejournal.kopertais4.or.id/mataraman/index.php/tah $\mathrm{dzib} /$ article/view/2202/2393.

Munirah, "Memorizing the Qur'an as Banjarese Bride-Price (A Study of Living Qur'an and Hadith)" Ulumuna, vol. 21, no. 2, 2017, pp. 278-297, https://doi.org/10.20414/ujis.v21i2.319.

Nurfuadah, Hilda, et.al, "Living Qur'an: Resepsi Komunitas Muslim pada Alquran (Studi Kasus di Pondok Pesantren atTarbiyyatul Wathoniyyah Desa Mertapada Kulon, Kec. Astatana Japura, Kab. Cirebon)" Diya al-Afkar, vol. 5, no. 1, 2017, pp. 1-14, http://dx.doi.org/10.24235/sqh.v5i01.3769.

R, Abd. Rahman, "Memahami Esensi Asmaul Husna dalam AlQur'an (Implementasinya sebagai Ibadah dalam Kehidupan)" Jurnal Adabiyah 11, no. 2, 2011, pp. 150-166. 
http://journal.uin-

alauddin.ac.id/index.php/adabiyah/article/view/1723/pdf.

Rafi, Muhammad, "Living Hadis: Studi atas Tradisi Sedekah Nasi

Bungkus Hari Jumat oleh Komunitas Sijum Amuntai" Jurnal

Living Hadis, vol. 4, no. 1, 2019, pp. 133-158,

http://ejournal.uin-

suka.ac.id/ushuluddin/Living/article/view/1647/1408.

Rahman, Syahrul, "Living Qur'an: Studi Kasus Pembacaan Al-

Ma'tsurat di Pesantren Khalid bin Walid Pasir Pengaraian

Kab. Rokan Hulu" Jurnal Syahadah, vol. 4, no. 2, 2016, pp. 49-71, http://dx.doi.org/10.32495/.v4i2.119.

Rahman, Ulfiani, "Karakteristik Perkembangan Anak Usia Dini" Lentera Pendidikan 12, no. 1, 2009: 46-57. https://doi.org/10.24252/lp.2009v12n1a4.

Ramadiputra, Ade Trial, "Pemaknaan Al-Qur'an dan Hadis dalam Tradisi Ritual Mandi Safar di Desa Momo Kecamatan Mamosalato Kabupaten Morowali Utara Provinsi Sulawesi Tengah Studi Living Qur'an” Tesis, Yogyakarta: Pascasarjana UIN Sunan Kalijaga, 2018.

Sa'diyah, Miftahus, "Islam and Local Culture: Living Qur'anic Studies in the Ngeruwat Bumi Culture in Balung Village" Nuansa, vol. 15, no. 2, 2018, pp. 321-332, http://dx.doi.org/10.19105/nuansa.v15i2.2061.

Safi'ah, Ranti \& Marhumah, "Pendidikan Karakter Mandiri Siswa MI Baiquniyyah dan Anak Binaan RSB Diponegoro" Abdau: Jurnal Pendidikan Madrasah Ibtidaiyah 1, no. 2, 2018. http://jurnal.stpi-

bim.ac.id/index.php/ABDAU/article/view/13.

Sholihah, Anisa Khabibatus, "Implementasi Living Qur'an di SMP Islam Al-Azhar 26 Yogyakarta" Tesis, Yogyakarta: Pascasarjana UIN Sunan Kalijaga, 2018.

Soekanto, Soerjono, Teori Sosiologi tentang Pribadi Masyarakat, Jakarta: Ghalia Indonesia, 1982.

Suhartono, Edi, "Perubahan Pola Pembelajaran PKn yang Tekstual ke Pola Kontekstual (CTL)" Jurnal Teori dan Praksis Pembelajaran, vol. 3, no. 1, 2018, pp. 1-12. http://journal2.um.ac.id/index.php/itppips/article/view/3 $\underline{883 / 2162}$.

Tirtayani, Luh Ayu, et.al., Perkembangan Sosial Emosional pada Anak Usia Dini, Yogyakarta: Graha Ilmu, 2014. 
Ulwan, Abdullah Nashih, Pendidikan Anak Menurut Islam: Kaidahkaidah Dasar, terj. Khalilullah Ahmas Masjkur Hakim, Bandung: PT Remaja Rosdakarya, 1992.

Ulwiyah, Nur, "Landasan Psikologi dan Aktualisasinya dalam Pendidikan Islam" Religi: Jurnal Studi Islam 6, no. 1, 2015, pp. 76-99. https://journal.unipdu.ac.id/index.php/religi/article/view/ $562 / 495$.

Yanti, Depi, "Konsep Akal dalam Perspektif Harun Nasution" Jurnal Intelektualita: Keislaman, Sosial, dan Sains 6, no. 1, 2017, pp. $51-62$. https://doi.org/10.19109/intelektualita.v6i1.1300. 